\title{
KETIDAKNYAMANAN TONGUE CRIB SEBAGAI FAKTOR RISIKO UNTUK KEBERHASILAN KOREKSI ANTERIOR TONGUE THRUST SWALLOW
}

\author{
Magdalena Lesmana
}

Fakultas Kedokteran Gigi Universitas Prof. Dr. Moestopo (Beragama)

\section{Keywords:}

Tongue Crib;

Anterior Tongue

Thrust Swallow

\section{Pendahuluan}

Anterior Tongue Thrust Swallow (ATTS) yaitu penelanan dengan mendorongkan lidah ke

\begin{abstract}
Anterior Tongue Thrust Swallow (ATTS), a swallowing pattern by pushing the tongue onto anterior dentition, can initiate malocclusion in the anterior region, which will create psychophysiological problems due to aesthetic, speech, and mastication disorders. The use of a Tongue Crib (TC) as a corrective device for ATTS is to block the force of tongue against the anterior teeth. Wearing a TC will have an experience of discomfort for the patient and can be an obstacle in using TC regularly, lengthening the period of treatment. A clinical trial with 25 subjects using TC in their retention period, and 48 patients only using Hawley retainer without crib as control, was carried out from September 2004 until May 2005 in the FKG UI Orthodontics clinic, the Orthodontics Clinic of Lembaga Kedokteran Gigi (Ladokgi) TNI AL R.E. Martadinata and in a specialist clinic. The survival analysis for the TC users, associated with sensor time, indicates that 25 of the TC users had not succeeded to correct ATTS. A discomfort questionnaire (DQ) was specifically designed for this study, consisting of 9 items. A significant result was that the discomfort experienced was one of the risk factor for the ineffectiveness of Tongue Crib in correcting ATTS.
\end{abstract}


estetik, ujaran, dan pengunyahan pada pasien dengan pola ATTS. ${ }^{1,2}$ Tingginya prevalensi ATTS $(73,7 \%)$ pada penelitian anak usia 7-13 tahun di Jakarta, dengan $88,2 \%$ di antaranya mempunyai maloklusi di regio anterior, perlu mendapat perhatian. Macam maloklusi yang ditemukan pada subjek penelitian tersebut adalah protrusi anterior atas $(38,7 \%)$, rotasi gigi-gigi anterior atas $(25,9 \%)$, flaring anterior atas $(9,4 \%)$, protrusi anterior bawah $(6 \%)$, dan kombinasi. ${ }^{3}$ Oleh karena itu, ATTS merupakan masalah yang harus dikoreksi, di samping maloklusi yang menyertainya. ${ }^{2}$

Kurangnya kepedulian dokter gigi dengan tetap membiarkan keberadaan ATTS selama perawatan maloklusi, dapat menghambat perawatan ortodonti pada pasien yang mempunyai ATTS dan akan memperpanjang masa perawatan. ${ }^{5}$ Relapse maloklusi dengan berbagai permasalahannya juga dapat timbul pada pasien yang masih mempunyai ATTS pada pasca perawatan ortodonti. Adanya relapse ini menjadikan mubazirnya perawatan yang telah dilakukan dan menimbulkan frustrasi baik bagi pasien maupun operator. ${ }^{6}$

Tongue Crib (Gambar 1) masih digunakan sampai saat ini dan berbagai macam alat dengan filosofi yang sama dengan crib juga telah dikembangkan dan digunakan untuk mengatasi ATTS (Gambar 2), tetapi keberhasilannya mengoreksi ATTS secara permanen perlu penelitian lebih lanjut. Kesulitan untuk mengatasi kebiasaan oral ini mungkin terjadi karena usaha yang dilakukan hanya bersifat mekanis dan tidak melalui pendekatan psikofisiologis. Filosofi crib hanya bertujuan untuk menghalangi pendorongan lidah ke anterior (to restrain) dan tidak ditujukan untuk mengubah perilaku lidah melalui pendekatan dan latihan (to retrain), sehingga bila alat crib dilepas pola ATTS kembali terjadi. Hal ini kurang disadari oleh operator yang menganggap penempatan crib dalam mulut dapat menyelesaikan masalah ATTS karena lidah akan beradaptasi terhadap posisinya dibelakang crib. ${ }^{4}$ Adanya ketidaknyamanan yang dirasakan pasien dengan keberadaan crib di dalam mulut karena mengganggu fungsi bicara, menelan serta penampilan tidak diperhatikan oleh operator. Ketidaknyamanan yang dirasakan oleh pasien pengguna crib akan menyebabkan alat crib tidak digunakan secara maksimal dan akan ${ }_{7}$ menimbulkan masalah relapse dikemudian hari.

Masih adanya perbedaan pendapat mengenai berhasil tidaknya alat crib untuk mengoreksi ATTS memerlukan penelitian lebih lanjut sampai seberapa jauh efektivitas TC untuk mengoreksi ATTS mengingat faktor ketidaknyamanan alat TC menyebabkan pasien tidak menggunakan alat sesuai aturan. Kerjasama yang kurang dengan adanya ketidaknyamanan yang ditimbulkan crib sangat berpengaruh pada keberhasilan perawatan koreksi ATTS. ${ }^{4}$ Untuk itu dilakukan evaluasi kerjasama yaitu jumlah jam pemakaian alat/hari dan dibandingkan antara pengguna Hawley retainer dengan TC dan tanpa TC yang mempunyai tingkat ketidaknyamanan yang berbeda. Hasilnya menunjukkan perbedaan bermakna yaitu kerja sama untuk pengguna HwR tanpa TC jauh lebih baik dibandingkan pengguna $\mathrm{TC}$.

Kuesioner Ketidaknyamanan yang terdiri dari 9 item dirancang untuk membandingkan rasa ketidaknyamanan pada pengguna alat HwR disertai TC terhadap pengguna alat HwR tanpa TC. Hasil analisis penelitian ini telah membuktikan kenyamanan merupakan alasan utama tidak digunakannya alat TC sesuai aturan sehingga dapat merupakan faktor risiko ketidakberhasilan alat retensi dengan TC sebagai alat koreksi ATTS dan juga sebagai alat retensi. Hal ini sesuai dengan pendapat Nanda bahwa kenyamanan alat merupakan salah satu faktor yang berpengaruh pada kerjasama ${ }^{7}$

\section{Bahan dan cara kerja}

Sebagai subjek penelitian pada saat dimulainya penelitian adalah 12 pasien ATTS dalam masa retensi 2-12 bulan yang sedang menggunakan Hawley retainer yang ditambahkan TC dan 13 pasien ATTS yang segera akan memasuki masa retensi dan akan menjadi pengguna Hawley retainer ditambahkan 
TC (gambar 1). Sebagai kontrol adalah 48 pasien dalam masa retensi menggunakan Hawley retainer saja (gambar 2). Subjek merupakan pasien yang sedang menjalani retensi yang sudah mempunyai rekam medik di tempat penelitian yaitu Klinik Ortodonti FKG

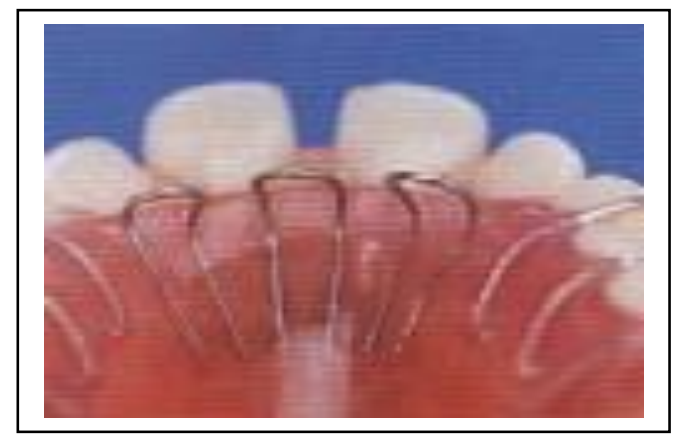

Gambar 1. Tongue Crib(TC)

(sumber:Space Maintainers Laboratory,1994)

Pada subjek dilakukan pemeriksaan klinis dan pencetakan lengkung geligi serta pemberian kuesioner Ketidaknyamanan (KKNYAM) yang terdiri dari 9 item. Evaluasi kerjasama dilakukan melalui pengisian data pasien mengenai jumlah jam pemakaian alat rata-rata per hari yang dilakukan evaluasinya tiap 2 minggu pada saat kunjungan kembali untuk pemeriksaan keberhasilan perawatan. Data yang diperoleh melalui kuesioner dan data evaluasi kerjasama dimasukkan menjadi data komputer. . Rasa ketidaknyamanan subjek dinyatakan dalam 4 skala pengukuran yaitu :0 = tidak ada ketidaknyamanan (sangat nyaman), $1=$ sedikit tidak nyaman (cukup nyaman), $2=$ tidak nyaman, 3 = sangat tidak nyaman.

Pengisian Kuesioner Ketidaknyamanan dilakukan sesuai dengan ketentuan waktu yang ditetapkan yaitu pada hari-1, minggu-1, bulan-1,
UI dan Klinik Subdepartement Ortodonti Lembaga Kedokteran Gigi (Ladokgi) TNI AL R.E. Martadinata dan di tempat praktek spesialis. Penelitian dilaksanakan dari bulan September 2004 sampai dengan Mei 2005.

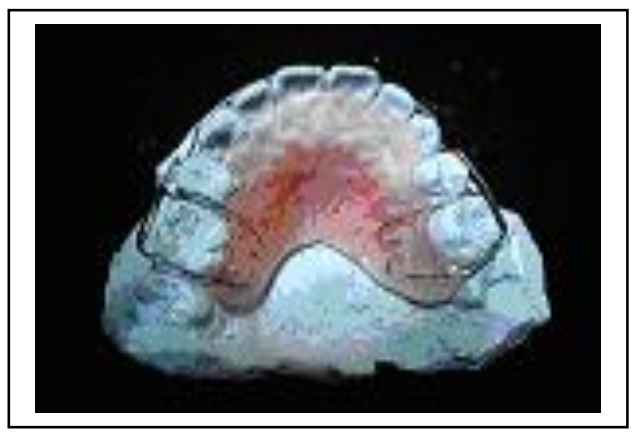

Gambar 2. Hawley Retainer(HwR)

karena menurut Ngan dkk, terdapat penurunan skala ketidaknyamanan dengan berjalannya waktu. ${ }^{8}$ Pada penelitian ini dilakukan pendataan ketidaknyamanan setelah 1 hari, 1 minggu dan 1 bulan setelah pemasangan alat.(modifikasi kuesioner Ngan dkk)

\section{Hasil}

Pada penelitian dengan desain kohort historikal, tidak diperoleh data insidens keberhasilan TC mengoreksi ATTS pada 12 subjek pengguna TC pada saat dimulainya penelitian.dengan rentang waktu sensor $110-$ 434 hari, dan pengguna Hawley retainer sebagai subjek kontrol dengan rentang waktu sensor 55 - 336 hari. (Tabel 1). 
Kuesioner Ketidaknyamanan pada pemasangan alat TC/HwR

\begin{tabular}{|c|c|c|c|c|c|c|c|c|c|c|c|c|}
\hline \multirow{3}{*}{ Kriteria } & \multicolumn{12}{|c|}{ Respons (\%) } \\
\hline & \multicolumn{3}{|c|}{$\begin{array}{c}\text { Tidak terasa } \\
\text { Ketidaknyamanan } \\
(0)\end{array}$} & \multicolumn{3}{|c|}{$\begin{array}{c}\text { Sedikit terasa } \\
\text { Ketidaknyamanan } \\
\text { (1) }\end{array}$} & \multicolumn{3}{|c|}{$\begin{array}{c}\text { Cukup terasa } \\
\text { Ketidaknyamanan } \\
\text { (2) }\end{array}$} & \multicolumn{3}{|c|}{$\begin{array}{c}\text { Sangat terasa } \\
\text { Ketidaknyamanan } \\
\text { (3) }\end{array}$} \\
\hline & H1 & M1 & B1 & H1 & M1 & B1 & H1 & M1 & B1 & H1 & M1 & B1 \\
\hline \multicolumn{13}{|l|}{ 1. berbicara } \\
\hline \multicolumn{13}{|l|}{ 2. menelan } \\
\hline \multicolumn{13}{|l|}{ 3. penampilan } \\
\hline \multicolumn{13}{|l|}{ 4. bersosialisasi } \\
\hline \multicolumn{13}{|l|}{ 5. melakukan aktivitas } \\
\hline \multicolumn{13}{|l|}{ sehari- hari } \\
\hline \multicolumn{13}{|l|}{$\begin{array}{l}\text { 7. mematuhi aturan } \\
\text { perawatan }\end{array}$} \\
\hline \multicolumn{13}{|l|}{$\begin{array}{l}\text { 8. hubungan alat dengan } \\
\text { gigi }\end{array}$} \\
\hline \multicolumn{13}{|l|}{$\begin{array}{l}\text { 9. hubungan alat dengan } \\
\text { jaringan lunak mulut }\end{array}$} \\
\hline \multicolumn{13}{|l|}{ Keterangan: } \\
\hline $\begin{array}{l}\mathrm{H} 1=\text { ketidaknyamanan pa } \\
\mathrm{M} 1=\text { ketidaknyamanan pac } \\
\mathrm{B} 1=\text { ketidaknyamanan pa }\end{array}$ & $\begin{array}{l}\text { a hari } \\
\text { min } \\
\text { bula }\end{array}$ & & & & & & & & & & & \\
\hline
\end{tabular}

Table 1. Periode Perawatan dalam hari berdasarkan waktu sensor TC dan HwR

\begin{tabular}{|c|c|c|c|c|c|c|c|c|c|c|c|}
\hline $\begin{array}{l}\text { WAKTU } \\
\text { (HARI) }\end{array}$ & $\mathrm{TC}$ & HwR & TOTAL & $\begin{array}{l}\text { WAKTU } \\
\text { (HARI) }\end{array}$ & $\mathrm{TC}$ & HwR & TOTAL & $\begin{array}{l}\text { WAKTU } \\
\text { (HARI) }\end{array}$ & $\mathrm{TC}$ & HwR & TOTAL \\
\hline 55 & & 1 & 1 & 138 & 1 & & 1 & 320 & & 1 & 1 \\
\hline 58 & & 1 & 1 & 141 & & 1 & 1 & 322 & & 1 & 1 \\
\hline 60 & & 1 & 1 & 145 & & 1 & 1 & 332 & & 1 & 1 \\
\hline 61 & & 1 & 1 & 152 & 1 & & 1 & 336 & & 2 & 2 \\
\hline 67 & & 1 & 1 & 153 & & 1 & 1 & 340 & 1 & & 1 \\
\hline 74 & & 2 & 2 & 160 & & 1 & 1 & 351 & 1 & & 1 \\
\hline 76 & & 1 & 1 & 176 & & 2 & 2 & 367 & 1 & & 1 \\
\hline 79 & & 1 & 1 & 203 & 1 & 1 & 2 & 368 & 1 & & 1 \\
\hline 81 & & 2 & 2 & 206 & & 1 & 1 & 434 & 1 & & 1 \\
\hline 83 & & 2 & 2 & 212 & & 2 & 2 & & & & \\
\hline 85 & & 1 & 1 & 239 & & 1 & 1 & & & & \\
\hline 89 & & 1 & 1 & 250 & & 1 & 1 & & & & \\
\hline 93 & & 1 & 1 & 252 & & 2 & 2 & & & & \\
\hline 100 & & 1 & 1 & 264 & & 2 & 2 & & & & \\
\hline 110 & 1 & & 1 & 265 & & 1 & 1 & & & & \\
\hline 114 & & 2 & 2 & 282 & & 1 & 1 & & & & \\
\hline 124 & 1 & & 1 & 287 & & 1 & 1 & & & & \\
\hline 128 & 1 & 1 & 2 & 288 & & 1 & 1 & & & & \\
\hline 129 & 1 & & 1 & 302 & & 1 & 1 & & & & \\
\hline 133 & & 1 & 1 & 316 & & 1 & 1 & & & & \\
\hline
\end{tabular}

Hasil uji ketidaknyamanan alat dengan Chi-square dan $t$ test menunjukkan perbedaan bermakna antara ketidaknyamanan alat TC dan HwR(Tabel 2; $\mathrm{p}=0,000)$. 
Tongue Crib

Tabel 2 Hasil data ketidaknyamanan pengguna Tcdan HwR

\begin{tabular}{|c|c|c|c|c|c|}
\hline \multirow[t]{2}{*}{ Item } & \multicolumn{2}{|c|}{$\operatorname{HwR}(\mathrm{N}=48)$} & \multicolumn{2}{|c|}{ TC $(\mathrm{N}=25)$} & \multirow[t]{2}{*}{ Nila $\mathrm{p}$} \\
\hline & $\mathbf{n}$ & $\%$ & $\mathbf{n}$ & $\%$ & \\
\hline $\begin{array}{l}\text { Nilai ketidaknyamnan pada pengguna alat } \\
\text { koreksi ATTS }\end{array}$ & & & & & $0,000 \%$ \\
\hline$<43$ (nyaman) & 47 & 97,9 & 3 & 12 & \\
\hline$\geq 43$ (tidaknyamaman) & 1 & 2,08 & 22 & 88 & \\
\hline HR & $11 ; 30$ & & $25 ; 55$ & & \\
\hline $95 \%$ CI HR & 19,6 & 18,$6 ; 20,6$ & 46,8 & 43,$3 ; 50,3$ & $0,000 \mathbb{1}$ \\
\hline Median (25-75 percentil) & 20 & $(18 ; 21,5)$ & 50 & $(45 ; 52)$ & \\
\hline
\end{tabular}

\$nilai p hasil perhitungan Fisher's exact

'nilai p hasil perhitungan Pearson chi2

"nilai $p$ hasil perhitungan Two-sample $t$ test with equal variances

Hasil penelitian ini sesuai dengan hasil penelitian terdahulu bahwa TC tidak nyaman. ${ }^{4,5}$ Ketidaknyamanan TC antara lain gangguan fungsi ujar, menelan, dan penampilan sebagaimana diutarakan subjek dalam isian kuesioner ketidaknyamanan. Hal ini menjadi alasan utama tidak digunakannya alat sesuai aturan. Menurut Nanda, kerja sama sangat dipengaruhi faktor ketidaknyamanan yang dirasakan pada perawatan. ${ }^{7}$
Evaluasi kerja sama dilakukan melalui pengisian kuesioner rata-rata jumlah jam pemakaian alat per-hari. Faktor Kerja sama sangat berpengaruh pada keberhasilan perawatan koreksi ATTS. ${ }^{4}$ Untuk membandingkan kerja sama pada pengguna TC dan HwR dilakukan uji Chi-square dan $t$ test (Tabel 3).

Tabel 3 Hasil evaluasi kerja sama untuk pengguna HwR dan TC

\begin{tabular}{|c|c|c|c|c|c|}
\hline \multirow[t]{2}{*}{ Item } & \multicolumn{2}{|c|}{ HwR (N=48) } & \multicolumn{2}{|c|}{$\mathrm{TC}(\mathrm{N}=25)$} & \multirow[t]{2}{*}{ Nilai p } \\
\hline & $\mathbf{N}$ & $\%$ & $\mathbf{N}$ & $\%$ & \\
\hline $\begin{array}{l}\text { Kerja sama subjek } \\
\text { berdasarkan jumlah jam } \\
\text { pemakaian alat/hari }\end{array}$ & & & & & \\
\hline $0=12-22$ (baik) & 44 & 92 & 2 & 8 & $0,000^{*}$ \\
\hline $1=5-11$ (tidak baik) & 4 & 8 & 23 & 92 & \\
\hline Rentangan & $12 ; 21$ & & $5 ; 17$ & & \\
\hline Rerata (95\% CI rerata) & 16,8 & $(16,1 ; 17,5)$ & 8,8 & $(7,4 ; 10,2)$ & $0,000^{\text {II }}$ \\
\hline $\begin{array}{l}\text { Median }(25-75 \\
\text { percentil) }\end{array}$ & 17 & $(15 ; 18)$ & 8 & $(6 ; 11)$ & \\
\hline $\begin{array}{l}\int_{\text {nilai } \mathrm{p} \text { has }} \\
\text { nilai p has } \\
{ }_{\text {II }} \text { nilai } \mathrm{p} \text { has }\end{array}$ & $\begin{array}{l}\text { ungan } \\
\text { ungan } \\
\text { ungan }\end{array}$ & $\begin{array}{l}\text { 's exact } \\
\text { n chi2 } \\
\text { ample t test }\end{array}$ & vari & & \\
\hline
\end{tabular}

Hasilnya menunjukkan terdapat perbedaan bermakna, kerja sama untuk pengguna HwR lebih baik dibandingkan pengguna TC. Nilai kerja sama diperoleh melalui pertanyaan pada lembar kuesioner, yaitu berapa lama subjek menggunakan alat dalam jam per hari. Menurut Sergl dkk, karakteristik kerja sama subjek, sangat dipengaruhi faktor ketidaknyamanan alat ${ }^{9}$ Pada Tabel 4 dilakukan uji $X^{2}$ dan $t$ test untuk melihat hubungan ketidaknyamanan alat dengan kerja sama. Pada penelitian ini terbukti faktor ketidaknyamanan mempunyai hubungan bermakna dengan kerja sama pengguna TC dan HwR. 
Magdalena Lesmana

Tabel 4 Pengaruh kenyamanan pada kerja sama subjek pengguna HwR dan TC

\begin{tabular}{|c|c|c|c|c|c|}
\hline \multirow[t]{2}{*}{ Item } & \multicolumn{2}{|c|}{ Pakai alat $\geq 12$ jam / hari } & \multicolumn{2}{|c|}{ Pakai alat $<12$ jam/hari } & \multirow[t]{2}{*}{ Nilai $\mathbf{p}$} \\
\hline & $\mathbf{N}$ & $\%$ & $\mathbf{N}$ & $\%$ & \\
\hline Ketidaknyamanan & & & & & $0,000 \ddagger$ \\
\hline $0=<43$ nyaman & 46 & 100 & 4 & 14,81 & \\
\hline $1=\geq 43$ tidak nyaman & 0 & 0 & 23 & 85,19 & \\
\hline ntangan & $11 ; 26$ & & $20 ; 55$ & & \\
\hline Rerata (95\% CI rerata) & 19,6 & 18,$6 ; 20.6$ & 46,8 & 43,$3 ; 50,3$ & $0,000^{\mathbb{q}}$ \\
\hline Median (25-75percentil) & 20 & $18 ; 21$ & 50 & $44 ; 52$ & \\
\hline \multirow[t]{2}{*}{ Keterangan: } & $\begin{array}{l}\text { hitungan Fis } \\
\text { hitungan Pe }\end{array}$ & & & & \\
\hline & itungan $\mathrm{Tu}$ & le $\mathrm{t}$ test with $\mathrm{e}$ & riances & & \\
\hline
\end{tabular}

\section{Pembahasan}

Dipilihnya pengguna HR sebagai kontrol berdasarkan teori maloklusi bukan hanya diakibatkan ATTS tetapi juga menjadi penyebab ATTS memberi kemugkinan HwR yang berfungsi sebagai retainer secara tidak langsung juga berfungsi sebagai alat anti ATTS. Ketidaknyamanan alat, menyebabkan HwR yang diberikan tambahan TC gagal berfungsi bukan hanya sebagai alat anti ATTS tetapi juga sebagai alat retainer. Hal itu disebabkan karena tidak digunakannya alat sesuai aturan, dengan alasan ketidaknyamanan sehingga mengakibatkan terjadinya relapse maloklusi dan retained ATTS. Keberhasilan HwR sebagai retainer telah dikemukakan oleh Graber yang menyatakan bahwa fungsinya sebagai retainer tetap efektif sampai saat ini. ${ }^{10}$ Masih adanya ATTS pada pengguna HwR dan TC menurut Hanson disebabkan falsafah alat yang hanya sebagai alat anti ATTS bukan merupakan solusinya. ATTS sebagai suatu penyimpangan perilaku lidah perlu dimodifikasi melalui latihan lidah. ${ }^{4}$ Ditetapkannya waktu minimal dalam penelitian ini adalah 4 bulan, karena menurut Ehrlich fungsi TC sebagai alat koreksi ATTS dinyatakan tidak efektif bila koreksi ATTS tidak terjadi setelah 4 bulan pemakaian alat ${ }^{10}$

\section{Kesimpulan dan saran}

Tongue crib yang masih digunakan saat ini sebagai alat anti ATTS memang tidak memerlukan perhatian dan pengetahuan khusus mengenai perilaku lidah. ${ }^{4}$ Selama ini, masih ditemukannya ATTS pada pasien dalam masa retensi dianggap merupakan kesalahan pasien yang tidak menggunakan TC sesuai petunjuk yaitu secara terus menerus sampai waktu yang tidak terbatas. Hal ini didukung oleh pernyataan Graber untuk menggunakan TC selama waktu yang tidak terbatas pada malam hari dan menggunakan HwR pada siang hari. ${ }^{11}$ Perlu diperhatikan perawatan pasien seutuhnya termasuk pengaruh psikologi pasien terhadap ketidaknyamanan alat. $^{9} \quad$ Terlebih lagi, penggunaan TC dalam waktu yang tidak terbatas mengekang kebebasan bergeraknya lidah yang dapat menyebabkan distorsi pada perilaku lidah dan bahkan perilaku pasien, dengan adanya gangguan estetik dan fungsi bicara.

Berdasarkan hasil penelitian yang menggambarkan tidak efektifnya TC sebagai alat untuk mengoreksi ATTS secara permanen ini, perlu penelitian lebih lanjut untuk mendapatkan suatu perawatan yang berdasarkan falsafah modifikasi perilaku lidah dan bukan menghalangi terjadinya pendorongan lidah ke 
depan yang hanya dapat dilakukan selama alat berada dalam mulut

\section{Daftar Pustaka}

1. Uhde MD. Longterm stability of the static occlusion after orthodontic treatment. Unpublished thesis, University of Illinois. Reviewed by Graber, T.M. in Am J Orthod, 1981; 80:228.

2. Hanson ML. and Barrett RH. Fundamentals Of Orofacial Myology. Charles C Thomas Publisher, Springfield, Illinois, 1988. p. 3-35; 165-183; 223-51.

3. Lesmana M. Prevalensi dan distribusi "Anterior tongue thrust swallow" pada maloklusi regio anterior. Laporan Penelitian Spesialisasi Ilmu Orthodonti. Fakultas Pasca Sarjana Universitas Indonesia, 1990.

4. Barrett RH. and Hanson ML. Oral Myofunctional Disorders. The CV Mosby Company, Saint Louis, 1974.
5. Moyers RE. Handbook Of Orthodontics, $4^{\text {th }}$ ed. Year Book Medical Publisher, Chicago, 1988.

6. Norton LA. and Gellin ME. Management of digital sucking and tongue thrust in children. Dental Clinics of North America, 1986.

7. Nanda RS. and Kierl MJ. Prediction of cooperation in orthodontic treatment. $\mathrm{Am} \mathrm{J}$ Orthod Dentofacial Orthop, 1992; 102:1, 15-21.

8. Ngan P, Kess B and Wilson S. Perception of discomfort by patients undergoing orthodontic treatment. Am J Orthod Dentofacial Orthop, 1989; 96:1, 47-53.

9. Sergl HG, Klages U and Zentner A. Functional and social discomfort during orthodontic treatment-effects on compliance and prediction of patients adaptation by personality variables. European Journal of Orthodontics, 2000; 22:307-15.

10. Ehrlich AB. Training Therapists For Tongue Thrust Correction. Charles C Thomas Publisher, Springfield, Illinois, 1970.

11. Graber TM, Vanarsall RL, Orthodontics Current Principles and Techniques, Vol. 2, $3^{\text {rd }}$ ed. Mosby Inc., 2000. p. 910-12. 